\title{
Recurrent attack of acute myocardial infarction complicated with ventricular fibrillation due to coronary vasospasm within a myocardial bridge: a case report
}

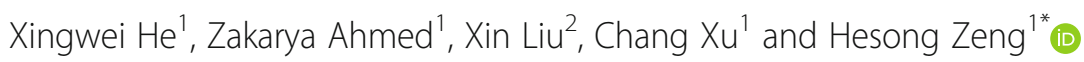

\begin{abstract}
Background: Myocardial bridge (MB) often an inoffensive condition that goes in one or more of the coronary arteries through the heart muscle instead of lying on its surface. MBs sometimes leads to myocardial ischemic symptoms such as chest pain, even an occurrence of myocardial infarction. However, reports of severe and recurrent cardiac adverse events related to the MBs are rare.

Case presentation: A 44-year-old male patient who suffered from a four-hour crushing chest pain ten years ago, was diagnosed as acute anterior ST-elevation myocardial infarction (STEMI). The initial findings of coronary angiography (CAG) showed MB was located in the middle part of the left anterior descending coronary artery (LAD). The patient was managed medically. Another re-attack of similar previous chest pain characteristics occured just after 3 days of discharge. Supra-arterial myotomy and CABG were the next adopted management. Postoperative progression was uneventful. However, 32 months after surgical treatment, the patient experienced an abrupt onset of chest pain accompanied by loss of consciousness. The ECG showed ventricular fibrillation (VF). After electrical cardioversion, an immediate CAG followed by CTA was performed which excluded thrombus or acute occlusion in the native coronary artery and an occlusion was observed at the end of the left internal mammary artery. An implantable cardioverter-defibrillator (ICD) was successfully performed for prevention of malignant arrhythmia. During ten years of follow-up, no complications have been identified.
\end{abstract}

Conclusions: Although MB is mostly benign, it may lead to significant cardiovascular consequences. Supra-arterial myotomy is an appropriate treatment option for this patient who failed to optimal medical therapy. Furthermore, ICD implantation must be considered in order to prevent malignant ventricular arrhythmia caused by continuous spasm resulting in ischemia. Further investigations are required to confirm the clinical effectiveness of these procedures.

Keywords: Vasospasm, Myocardial bridge, Myocardial infarction, Ventricular fibrillation, Implantable Cardioverterdefibrillator

\footnotetext{
* Correspondence: Zenghs@tjh.tjmu.edu.cn

'Department of Cardiology, Tongji Hospital, Tongji Medical College,

Huazhong University of Science and Technology, 1095\# Jiefang Ave, Wuhan 430030, China

Full list of author information is available at the end of the article
}

(c) The Author(s). 2020 Open Access This article is licensed under a Creative Commons Attribution 4.0 International License, which permits use, sharing, adaptation, distribution and reproduction in any medium or format, as long as you give appropriate credit to the original author(s) and the source, provide a link to the Creative Commons licence, and indicate if changes were made. The images or other third party material in this article are included in the article's Creative Commons licence, unless indicated otherwise in a credit line to the material. If material is not included in the article's Creative Commons licence and your intended use is not permitted by statutory regulation or exceeds the permitted use, you will need to obtain permission directly from the copyright holder. To view a copy of this licence, visit http://creativecommons.org/licenses/by/4.0/ The Creative Commons Public Domain Dedication waiver (http://creativecommons.org/publicdomain/zero/1.0/) applies to the data made available in this article, unless otherwise stated in a credit line to the data. 


\section{Background}

The coronary arteries are commonly lying on the surface of the myocardium. A segment of one or more of the major coronary arteries that have an anomaly characterization of a typical intramyocardial direction is defined as a myocardial bridge (MB, usually located in the middle segment of the LAD). MB may lead to a systolic luminal narrowing, which is often delayed to the diastolic period, especially during heavy exercise that causes a reduction of coronary artery blood perfusion [1]. Due to the specific hemodynamic states caused by $\mathrm{MB}$, the rate of proximal coronary atherosclerosis is $86 \%$. MB was first reported by Reyman in 1737 , and then it was confirmed angiographically by Porstmann and Iwig in 1960 [2]. The prevalence has been reported to range from $5.4-85 \%$ in autopsy series to $0.5-29.4 \%$ on coronary angiography [3].

On CAG, MB typically presents as a systolic narrowing, or "milking" of the artery, with a "step-down" and "step-up" demarcating the influenced area, and partial or complete decompression in the diastolic period [4]. Although $\mathrm{MB}$ can be found in any epicardial coronary artery, it commonly involves the mid-portion of the LAD [5]. $\mathrm{MB}$ is often considered as a benign variation due to the fact that the narrowing effect of the vessel commonly occurs during systole, while most of the myocardial demand for blood flow occurs during the diastole. Rarely, the compression of a coronary artery by the MB can be associated with clinical events of myocardial ischemia and even cause myocardial infarction, malignant arrhythmias, or sudden cardiac death (SCD).

In this article, we describe a patient who presented with a history of recurrent episodes of myocardial infarction, resulting from vasospasm within $\mathrm{MB}$ located in the mid-segment of the LAD, which then complicated to ventricular fibrillation. We report the results of the therapeutic strategy and long-term outcome.

\section{Case presentation}

A 44-year-old male patient presented to the emergency department of our hospital ten years ago with crushing chest pain persisting for $4 \mathrm{~h}$ after heavy labor. Hehad 5 years history of hypertension and no history of diabetes, smoking, and substance abuse. Physical examination revealed normal blood pressure in arms and legs with no evidence of an arm-leg gradient. Initial electrocardiography (ECG) showed elevated ST-segment (1-4 mm) at the anterior leads $V_{1}$ to $V_{6}$ (Fig. 1a). Blood test showed elevated myocardial troponin I levels of $0.5 \mathrm{ng} / \mathrm{ml}$ (normal range $0.00-0.04 \mathrm{ng} / \mathrm{ml}$ ), creatine kinase-MB of 11.9 $\mathrm{ng} / \mathrm{ml}$ (normal range $0.3-4.3 \mathrm{ng} / \mathrm{ml}$ ). The patient was diagnosed as acute anterior ST-elevation myocardial infarction and then underwent emergency catheterization. The initial findings of the CAG showed approximately
$10 \mathrm{~mm}$ in length, with $50 \%$ vascular stenosis during the systolic period in the middle part of theLAD and normal during the diastolic period (Fig. 2a-b). The antegrade blood flow in the LAD distal to the MB segment was normal (TIMI III) without any evidence of thrombus or spontaneous coronary artery dissections. All the other coronary vessels appeared normal. The patient's symptoms were stable, and was discharged after 1 week of hospitalisation. However, merely three days postdischarge, the patient suffered from another episode of chest pain despite the use of $\beta$-blocker (metoprolol 47.5 mg once a day) and calcium channel blockers (dihiazem $90 \mathrm{mg}$ twice a day). He had an elevated myocardial troponin I level of $30 \mathrm{ng} / \mathrm{ml}$. ECG showed elevated STsegment at the precordial leads $V_{1}-V_{6}$, echocardiogram reported abnormal segmental wall motion with an ejection fraction of $45 \%$. The patient was diagnosed as a recurrent of STEMI.Supra-arterial myotomy, and CABG management were the treatment choice, which was successfully performed through a median sternotomy. Postdischarge medications was prescribed taking cardiovascular risk factors into consideration. Thereafter, no special discomfort was reported.

Thirty-two months after the surgery, the patient experienced another attack of chest pain in the morning along with a loss of consciousness on his way to the hospital in an ambulance. Cardiac monitoring showed VF (Fig. 1b). Cardiopulmonary resuscitation followed by electrical cardioversion restored normal sinus rhythm. He had two further episodes of VF at the hospital which was electrically cardioverted to a borderline ventricular autonomous rhythm and eventually sinus rhythm. A prompt CAG followed by coronary CTA was performed which confirmed an occlusion at the end of the LIMA (Fig. 2c). The time of occlusion was not clear. Based on these findings, we considered ischemia-induced arrhythmia precipitated by coronary vasospasm as the most likely cause. According to the most current recommendation guidelines [6], an ICD (Fig. 2d) was implanted to prevent SCD as a consequence of malignant ventricular arrhythmia. The patient was discharged on aspirin, statin, beta-blockers, and calcium channel blocker.

During ten years of follow-up, the patient has never experienced any angina or myocardial infarction. The ICD readings demonstrated no ventricular arrhythmias (Fig. 1c). He is still under close and long-term follow-up.

\section{Discussions and conclusions}

$\mathrm{MB}$ is a common anatomical anomalyand mostly involves mid to distal parts of the LAD. On IVUS, the tunneled segment of LAD is of variable degree of compression that persists into diastole with the typical finding of the "half-moon phenomenon". For a long 


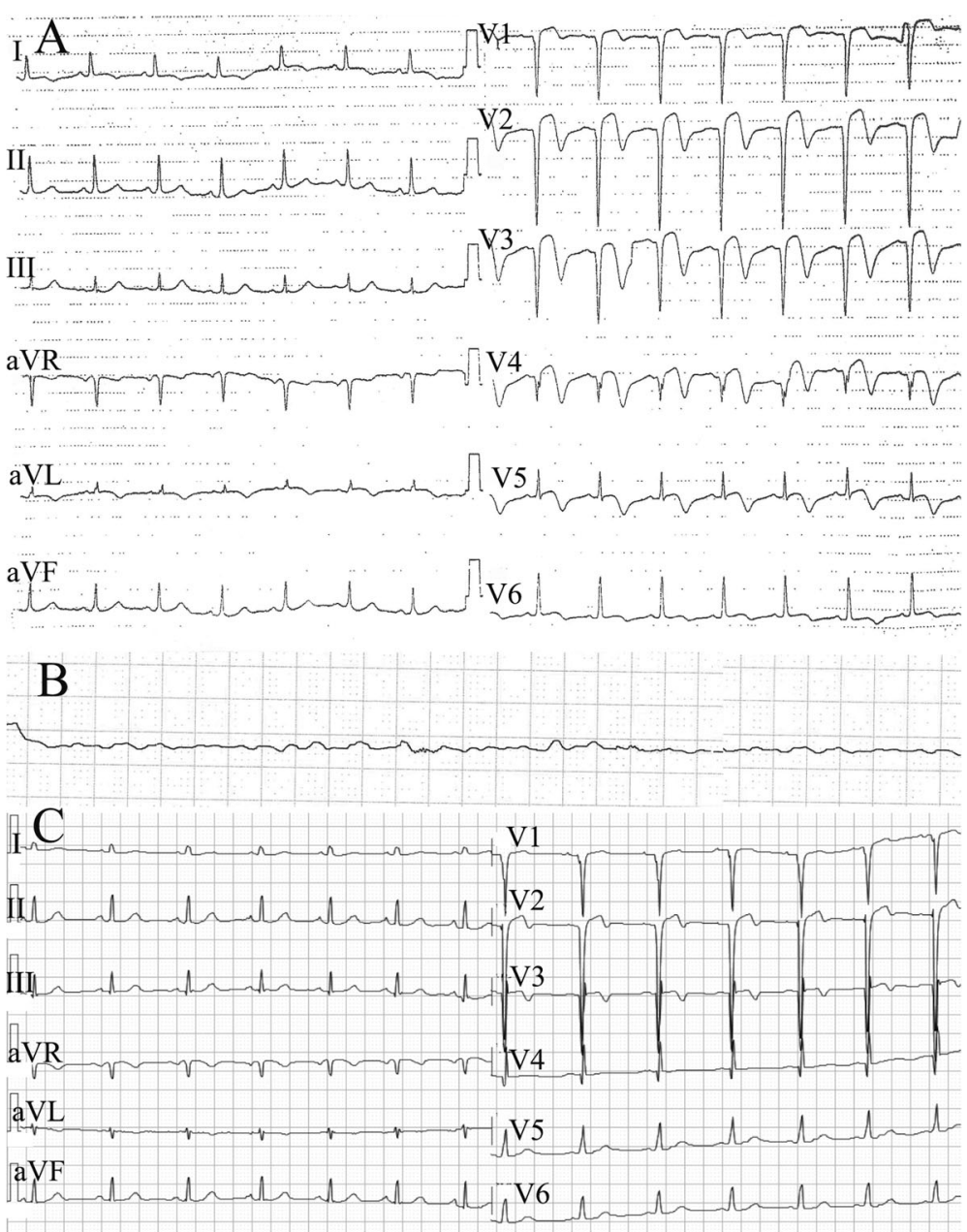

Fig. 1 The first ECG revealed typically convex ST-segment in the V1 to V4 leads, followed by inverted T waves in the precordial leads (a); the second ECG recorded from a cardiac monitoring 32 months after Supra-arterial myotomy and CABG management showed VF (b); ECG was obtained after ICD implantation during patient follow-up (c)

time, $\mathrm{MB}$ has been considered as a benign anatomic variation since the pressing of the coronary artery independently occurs during systole, which contains minimal blood perfusion to the heart muscle. However, several studies have supported the fact that $\mathrm{MB}$ can induce some fatal conditions, such as coronary thrombosis, spasm, acute coronary syndrome, transient ventricular dysfunction, takotsubo syndrome, life-threatening ventricular arrhythmias and/or SCD $[7,8]$.

There are several proposed mechanisms over which $\mathrm{MB}$ is supposed to cause myocardial ischemia and related symptoms. First, phasic systolic compression of the coronary artery leads to a persistent mid-to-late diastolic reduction in the vessel diameter. During exertional tachycardia, the relatively greater shortening of diastole than systole and the reduction of ventricular filling causes a decrease in coronary flow leading to myocardial ischemia [9-11]. Secondly,"milking" may lead to systolic retrograde intracoronary flow and complete blood flow disruption in the coronary artery with increased shear stress. This is a cause for the characteristic progression of atherosclerosis in the proximal segment of the MB, whereas the bridged segment stays relatively free from atherosclerosis [12]. Finally, the dysfunction of coronary endothelial and coronary vasospasm has also been proposed as an important mechanism for myocardial ischemia [13].

The current case report discusses a recurrent myocardial infarction with complicated ventricular fibrillationdue to coronary spasm in the MB site. CAG did not reveal fixed arteriosclerotic lesion in LAD but found that there was $\mathrm{MB}$, which displayed stenosis during the systole period. Although a provocation test was not attempted during CAG, considering the patient's symptoms and ECG findings, webelieve the MB was responsible for the coronary vasospasm.

Currently, the management of MB in symptomatic patients is still argumentative. First-line treatment of the 

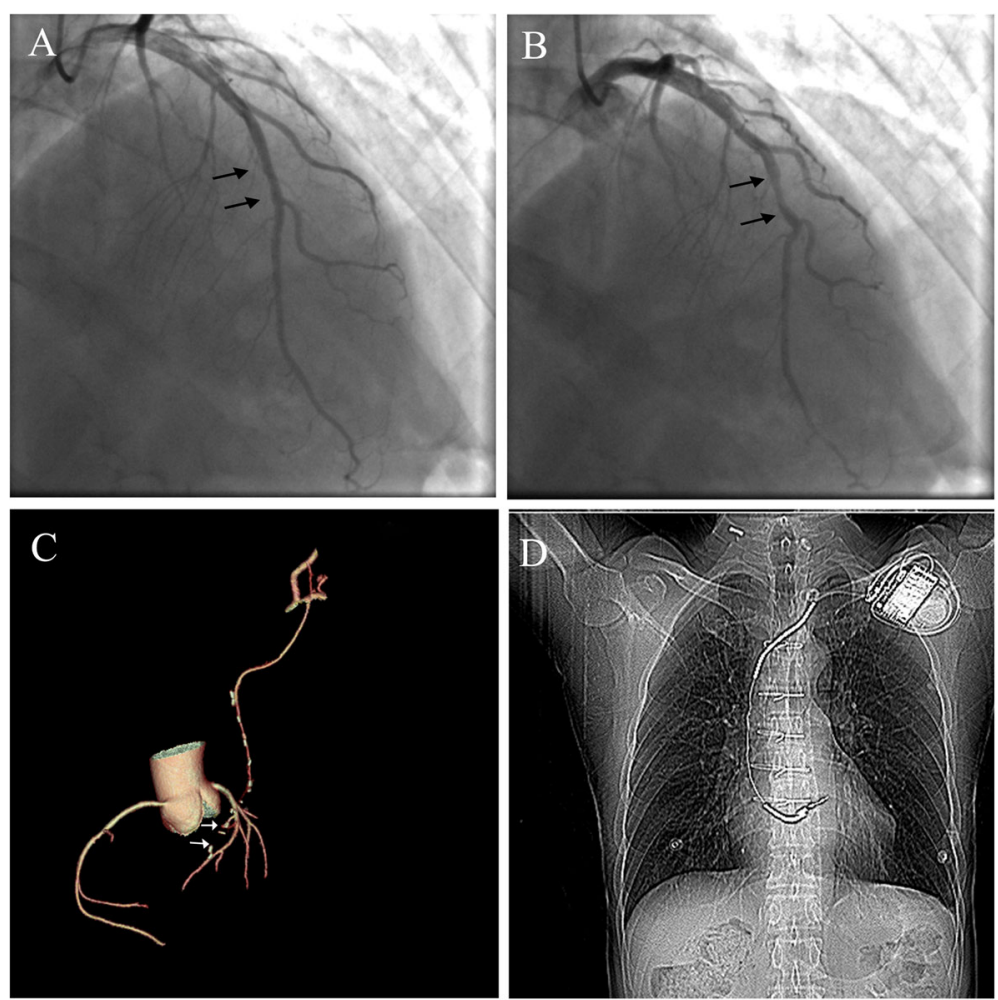

Fig. 2 RAO cranial view of the LAD at baseline displaying MB segment during systolic period (a black arrows), and diastolic period (b black arrows); volume-rendered 3-dimensional reconstruction displaying occlusion at the end of the LIMA (c white arrows); a chest radiograph showing the ICD device and its lead location $\mathbf{d}$

symptoms secondary to MB consists of calcium-channel blockers and beta-blockers [14]. Nitratesare contraindicated because of the excessive contraction due to secondary tachycardia and reflex sympathetic nerve activation [15]. For the intractable symptoms that responded poorly to conservative medical treatment, other therapeutic options have been attempted, such as coronary stent, supra-arterial myotomy, and CABG. However, despite the fact that coronary stent implantation may improve the abnormal hemodynamics and recover symptoms no research had verified the perfusion stability of the myocardium when a perfusion defect was present before stent implantation.

Surgical management should be the first choice for patients who have symptoms related to $\mathrm{MB}$ and have failed optimal medical therapy [16]. The options for the surgical management of $M B$ include supra-arterial myotomy, CABG, or both $[17,18]$. Surgical technique choices depend on $\mathrm{MB}$ features and local hospital competency. Supra-arterial myotomy management help to reduce patient symptoms, prevents the incidence of local myocardial ischemia and increases coronary blood flow, but there are risks such as ventricular aneurysm formation, wall perforation, and post-operative subendocardial hemorrage. Long-term complications such as myotomy scarring, specifically in MBs that lay deeper, may occur on the area over the entire artery resulting in recurrence of compression. These risks and complications could be avoided by bypassing the MB segment, which has the advantage of alleviating future ischemia by undergoing a CABG surgery [19]. However, long-term bypass patency secondary to competitive flow may be affected when bypass and myotomy are performed without proximal coronary occlusion. Important points to be noted are that: supra-arterial myotomy is the first choice for symptomatic patients who have failed to achieve optimal medical therapy. Bypass surgery should be performed in combination with or instead of supra-arterial myotomy when there is a proximal coronary obstruction or if there are technical considerations that preclude myotomy (e.g., extensive, deep, or tortuous MB). Due to the relatively deep location of the MB in the current case, bypass surgery combined with myotomy was carried out to achieve collected benefits of both surgical techniques and prevent further complications. However, the distal CABG graft was occluded, probably due to competitive flow. For patients who have experienced VF due to vasospasm, an ICD implantation might be a therapeutic option for preventing SCD. 
The current report highlights the association between $\mathrm{MB}$ and significant cardiovascular consequences. Supraarterial myotomy is an appropriate treatment option for symptomatic patients who have failed optimal medical therapy. For patients who experienced a ventricular fibrillation arrhythmic complication, an ICD implantation is the suitable therapeutic option for the secondary prevention of SCD. However, the best treatment strategy for patients with $\mathrm{MB}$ still requires more clinical case evaluations and further randomized study.

\section{Abbreviations}

MB: Myocardial bridge; CABG: Coronary artery bypass grafting; CAG: Coronary angiography; LAD: Left anterior descending coronary artery; LIMA: Left internal mammary artery; ICD: Implantable cardioverter-defibrillator; CTA: Computed tomography angiography; VF: Ventricular fibrillation; SCD: Sudden cardiac death; ECG: Electrocardiography; TIMI: Thrombolysis in myocardial infarction; IVUS: Intravascular ultrasound

\section{Acknowledgments}

We thank Menaka Dhuromsingh for linguistic assistance during the preparation of this manuscript

\section{Authors' contributions}

$X H, Z A$, and $X L$ collected the data and images and wrote the manuscript. $\mathrm{XH}, \mathrm{CX}$, and $\mathrm{HZ}$ directed the patient's medical care. $\mathrm{CX}$ and $\mathrm{HZ}$ conducted coronary angiography and acquired coronary images. $\mathrm{HZ}$ supervised all the diagnostic and therapeutic measures. All authors read and approved the final manuscript.

\section{Authors' information}

Not applicable.

\section{Funding}

Our work reported here was supported by the Key Project of Health and Family Planning Commission of Hubei Province, China (No.WJ2017Z012), and the National Natural Science Foundation of China (No.81800411). The funding bodies were not involved in the design of the study; collection, analysis, or interpretation of the data; or writing the manuscript.

\section{Availability of data and materials}

All relevant data supporting the conclusions of this article are included in the article

\section{Ethics approval and consent to participate}

Our study protocols were approved by the ethical committee of Tongji Hospital, Tongji Medical College, Huazhong University of Science and Technology, Wuhan, China. Written consent to participate was obtained from the patient in this study.

\section{Consent for publication}

Written informed consent was obtained from the patient for publication of this case report and any accompanying images.

\section{Competing interests}

The authors declare that they have no competing interests.

\section{Author details}

${ }^{1}$ Department of Cardiology, Tongji Hospital, Tongji Medical College, Huazhong University of Science and Technology, 1095\# Jiefang Ave, Wuhan 430030, China. ²Department of Operation Room, Tongji Hospital, Tongji Medical College, Huazhong University of Science and Technology, Wuhan, China.
Received: 27 January 2020 Accepted: 3 August 2020

Published online: 24 August 2020

\section{References}

1. Hao Z, Xinwei J, Ahmed Z, Huanjun P, Zhanqi W, Yanfei W, Chunhong C, Chan Z, Liqiang F. The outcome of percutaneous coronary intervention for significant atherosclerotic lesions in segment proximal to myocardial bridge at left anterior descending coronary artery. Int Heart J. 2018:17-179.

2. Porstmann W, Iwig J. Intramural coronary vessels in the angiogram. Fortschr Geb Rontgenstr Nuklearmed. 1960;92:129-33.

3. Möhlenkamp S, Hort W, Ge J, Erbel R. Update on myocardial bridging Circulation. 2002;106(20):2616-22.

4. Juilliere $Y$, Berder $V$, Suty-Selton $C$, Buffet $P$, Danchin N, Cherrier F. Isolated myocardial bridges with angiographic milking of the left anterior descending coronary artery: a long-term follow-up study. Am Heart J. 1995; 129(4):663-5.

5. Cicek D, Kalay N, Muderrisoglu H. Incidence, clinical characteristics, and 4year follow-up of patients with isolated myocardial bridge: a retrospective, single-center, epidemiologic, coronary arteriographic follow-up study in southern Turkey. Cardiovasc Revasc Med. 2011;12(1):25-8.

6. Wann LS, Curtis $A B$, January $C T$, Ellenbogen $K A$, Lowe JE, Estes NM, Page RL, Ezekowitz MD, Slotwiner DJ, Jackman WM, et al. 2011 ACCF/AHA/HRS focused update on the management of patients with atrial fibrillation (updating the 2006 guideline). Circulation. 2011;57(2):223-42.

7. Lee MS, Chen $\mathrm{CH}$. Myocardial bridging: an up-to-date review. J Invasive Cardiol. 2015:27(11):521.

8. Kikuchi S, Okada K, Hibi K, Maejima N, Matsuzawa Y, Konishi M, Kimura Y, Kosuge M, Iwahashi N, Ebina T, et al. Myocardial infarction caused by accelerated plaque formation related to myocardial bridge in a young man. Can J Cardiol. 2018;34(12):1687 e1613-1687 e1615.

9. Yukio I, Yoko K, Ehiichi K, Toshiharu I. (1) coronary events caused by myocardial bridge. Ann Vasc Dis. 2009;2(2):79-94.

10. Ge J, Erbel R, Rupprecht HJ, Koch L, Kearney P, Gorge G, Haude M, Meyer J. Comparison of intravascular ultrasound and angiography in the assessment of myocardial bridging. Circulation. 1994:89(4):1725-32

11. Cerrato E, Barbero U, D'Ascenzo F, Taha S, Biondi-Zoccai G, Omede P, Bianco M, Echavarria-Pinto M, Escaned J, Gaita F, et al. What is the optimal treatment for symptomatic patients with isolated coronary myocardial bridge? A systematic review and pooled analysis. J Cardiovasc Med. 2017; 18(10):758-70.

12. Sun $X$, Chen H, Xia L, Zhao D, Ding W, Wang C. Coronary artery bypass grafting for myocardial bridges of the left anterior descending artery. J Card Surg. 2012;27(4):405-7.

13. Herrmann J, Higano ST, Lenon RJ, Rihal CS, Lerman A. Myocardial bridging is associated with alteration in coronary vasoreactivity. Eur Heart J. 2004; 25(23):2134-42

14. Alessandri N, Dei Giudici A, De Angelis S, Urciuoli F, Garante MC, Di Matteo A. Efficacy of calcium channel blockers in the treatment of the myocardial bridging: a pilot study. Eur Rev Med Pharmacol Sci. 2012;16(6):829-34.

15. Hongo $Y$, Tada $H$, Ito $K$, Yasumura $Y$, Miyatake $K$, Yamagishi $M$. Augmentation of vessel squeezing at coronary-myocardial bridge by nitroglycerin: study by quantitative coronary angiography and intravascular ultrasound. Am Heart J. 1999;138(2 Pt 1):345-50.

16. Xu Z, Wu Q, Li H, Pan G. Myotomy after previous coronary artery bypass grafting for treatment of myocardial bridging. Circulation. 2011;123(10): 1136-7.

17. Ekeke CN, Noble S, Mazzaferri E Jr, Crestanello JA. Myocardial bridging over the left anterior descending: Myotomy, bypass, or both? J Thorac Cardiovasc Surg. 2015:149(4):e57-8.

18. Bockeria LA, Sukhanov SG, Orekhova EN, Shatakhyan MP, Korotayev DA, Sternik L. Results of coronary artery bypass grafting in myocardial bridging of left anterior descending artery. J Card Surg. 2013;28(3):218-21.

19. Attaran S, Moscarelli M, Athanasiou T, Anderson J. Is coronary artery bypass grafting an acceptable alternative to myotomy for the treatment of myocardial bridging? Interact Cardiovasc Thorac Surg. 2013;16(3):347-9.

\section{Publisher's Note}

Springer Nature remains neutral with regard to jurisdictional claims in published maps and institutional affiliations. 